\title{
The impact of outdoor air pollutants on outpatient visits for respiratory diseases during 2012-2016 in Jinan, China
}

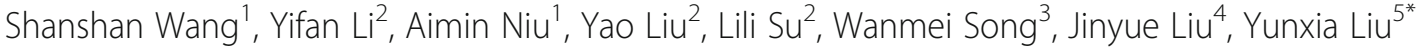 \\ and Huaichen $\mathrm{Li}^{2^{*}}$
}

\begin{abstract}
Background: Few studies have investigated the associations between outdoor air pollution and outpatient visits for respiratory diseases (RDs) in general population.

Methods: We collected daily outpatient data of primary RDs from five hospitals in Jinan during January 2012 and December 2016, as well as daily measurements of air pollutants from the Jinan Environmental Monitoring Center and daily meteorological variables from the China Meteorological Data Sharing Service System. A generalized additive model (GAM) with quasi-Poisson regression was constructed to estimate the associations between daily average concentrations of outdoor air pollutants $\left(\mathrm{PM}_{2.5}, \mathrm{PM}_{10}, \mathrm{SO}_{2}, \mathrm{NO}_{2}, \mathrm{CO}\right.$ and $\left.\mathrm{O}_{3}\right)$ and daily outpatient visits of RDs after adjusting for long-time trends, seasonality, the "day of the week" effect, and weather conditions.

Subgroup analysis stratified by gender, age group and the type of RDs was conducted.

Results: A total of 1,373,658 outpatient visits for RDs were identified. Increases of $10 \mu \mathrm{g} / \mathrm{m}^{3}$ in $\mathrm{PM}_{2.5}, \mathrm{PM}_{10}, \mathrm{NO}_{2}, \mathrm{CO}$ and $\mathrm{O}_{3}$ were associated with $0.168 \%$ ( $\left.95 \% \mathrm{Cl}, 0.072-0.265 \%\right), 0.149 \%$ (95\% Cl, $\left.0.082-0.215 \%\right), 0.527 \%(95 \% \mathrm{Cl}, 0.211-0.843 \%)$, $0.013 \%(95 \% \mathrm{Cl}, 0.003-0.023 \%)$, and $0.189 \%(95 \% \mathrm{Cl}, 0.032-0.347 \%)$ increases in daily outpatient visits for RDs, respectively. $\mathrm{PM}_{2.5}$ and $\mathrm{PM}_{10}$ showed instant and continuous effects, while $\mathrm{NO}_{2}, \mathrm{CO}$ and $\mathrm{O}_{3}$ showed delayed effects on outpatient visits for RDs. In stratification analysis, $\mathrm{PM}_{2.5}$ and $\mathrm{PM}_{10}$ were associated with acute RDs only.
\end{abstract}

Conclusions: Exposure to outdoor air pollutants including $\mathrm{PM}_{2.5}, \mathrm{PM}_{10}, \mathrm{NO}_{2}, \mathrm{CO}$ and $\mathrm{O}_{3}$ associated with increased risk of outpatient visits for RDs.

Keywords: Air pollution, Outpatient visits, Respiratory diseases, Generalized additive model

\section{Introduction}

The adverse effects of outdoor air pollution have attracted intensive attention worldwide. In recent years, China as a heavily air-polluted country has strengthened environmental monitoring, which contributed large amounts of data and provided a unique opportunity to assess the health effects of air pollution [1, 2]. Many recent studies conducted in China have demonstrated that outdoor air pollutants could increase the risk for mortality $[3,4]$, respiratory diseases (RDs) [5, 6], and cardiovascular diseases $[7,8]$.

\footnotetext{
*Correspondence: yunxialiu@163.com; lihuaichen@163.com

${ }^{5}$ Department of Biostatistics, School of Public Health, Shandong University, Jinan 250012, Shandong, China

${ }^{2}$ Department of Respiratory Medicine, Shandong Provincial Hospital affiliated to Shandong University, Jinan 250021, Shandong, China

Full list of author information is available at the end of the article
}

In China, the outdoor air pollution showed a significant regional difference. The composition and levels of pollutants vary from city to city because they are largely depended on meteorological conditions, local terrain and emission sources $[9,10]$. For example, the severest air pollution is appear in most cities in north and central China. Moreover, specific populations may be at different risk of air pollution because of the different susceptibility and vulnerability to adverse effects of pollutants [11]. For these reasons, the effect size of air pollution of one region cannot reflect that of another.

Jinan, a capital city located in the east of China, has been experiencing serious air pollution which poses huge threats to people's health of respiratory system. Previous studies conducted in Jinan have shown that exposure to

(C) The Author(s). 2018 Open Access This article is distributed under the terms of the Creative Commons Attribution 4.0 International License (http://creativecommons.org/licenses/by/4.0/), which permits unrestricted use, distribution, and 
air pollution is associated with overall-mortality and cause-specific mortality [12], hospital emergency room visits for RDs [13], and acute exacerbations of chronic obstructive pulmonary disease hospitalization [14]. It is noteworthy that these previous studies have been focused on severe cases of RDs, which usually occur in a small proportion of the population in very poor health. The effects of air pollution on the majority of the population remain largely unknown. The outpatient services is open to all diseases with various severity and is not restricted by bed availability, thus could reflect the medical need of most people. Therefore, the effects of air pollution on outpatient visits for RDs need to be explored in large-scale studies.

In the present study, we investigated the associations between outdoor air pollutants and outpatient visits for RDs in Jinan. To do so, we used data from approximately 1.37 million outpatient records in five hospitals between 2012 and 2016 .

\section{Methods \\ Data collection}

The daily count of outpatient visits for primary RDs from January 1, 2012, to December 31, 2016 were obtained from five hospitals in Jinan city, including Shandong Provincial Hospital Affiliated to Shandong University, Qilu Children's Hospital of Shandong University, Jinan Central Hospital, Qianfo Mountain Hospital and The Second Hospital of Shandong University. The medical records include patients' name, age, gender, date of hospital visiting and all diagnoses. We collected data on four main RDs, including pneumonia, acute bronchitis, asthma and chronic bronchitis. Other diagnoses such as interstitial pneumonia, aspiration pneumonia and endogenous lipid pneumonia were excluded because they were few in number.

Data on daily 24-h mean concentrations of $\mathrm{PM}_{10}$, $\mathrm{PM}_{2.5}, \mathrm{SO}_{2}, \mathrm{NO}_{2}, \mathrm{CO}$ and $\mathrm{O}_{3}$ recorded by 14 monitoring stations were obtained from the Environmental Monitoring Center of Jinan. The daily concentration of each pollutant was calculated as the mean of the concentrations recorded by 14 monitoring stations. Besides, daily temperature, humidity, air pressure and wind speed during the study period were downloaded from the China Meteorological Data Sharing Service System (https://data.cma.cn/en).

\section{Statistical analysis}

In descriptive analysis, mean, standard deviation (SD), minimum (Min), maximum (Max), 25th percentile $\left(\mathrm{P}_{25}\right)$, 50th percentile $\left(P_{50}\right)$ and 75 th percentile $\left(P_{75}\right)$ were used to describe the data on air pollutants, meteorological parameters and outpatient visits. Spearman correlation was used to examine the relationships between air pollutants and meteorology parameters.

Generalized additive model (GAM) is a flexible and effective technique for estimating the unknown non-linear relationship between health effects and air pollution $[15,16]$. It does not require the shape of the response curve as a priori knowledge, and allows for nonparametric adjustments for nonlinear confounding effects [17]. Since the outpatient visits typically follow a quasi-Poisson distribution [16, 18], GAM with quasi-Poisson regression were constructed to examine the associations between air pollution and RDs outpatient visits. A penalized smoothing spline function [19] was used to adjust for long-term trends and seasonality in daily outpatient visits and potential non-linear effects of meteorological factors. Specifically, we used 7 degrees of freedom (df) per year for calendar time, and $4 \mathrm{df}$ for mean temperature, relative humidity, air pressure and wind speed according to the Akaike's information criterion (AIC) [20]. A smaller AIC value indicates a better fitting model [16]. In addition, the model was adjusted for day of the week (DOW) to control the day-in-week of the outpatient visits. Briefly, the following model was fitted:

$$
\begin{aligned}
\log \mathrm{E}(\mathrm{Yt})= & \text { Intercept }+\beta \mathrm{Zt}+\mathrm{s}(\text { time }, \mathrm{df}=7) \\
& +\mathrm{DOW}+\mathrm{s}(\text { temperature }, \mathrm{df}=4) \\
& +\mathrm{s}(\text { humidity }, \mathrm{df}=4) \\
& +\mathrm{s}(\text { pressure }, \mathrm{df}=4) \\
& +\mathrm{s}(\text { wind speed }, \mathrm{df}=4)
\end{aligned}
$$

where $E(Y t)$ is expected number of daily outpatient visits for RDs on day $\mathrm{t} ; \beta$ is the regression coefficient; $\mathrm{Zt}$ is the daily concentration of air pollutant on day $t ; s()$ denotes the smoother based on the penalized smoothing spline; DOW is the day of the week as a categorical variable.

In the present study, single-pollutant models were firstly fitted for $\mathrm{PM}_{2.5}, \mathrm{PM}_{10}, \mathrm{SO}_{2}, \mathrm{NO}_{2}, \mathrm{CO}$ or $\mathrm{O}_{3}$ on the same day and up to 5 days (lag0, lag1, lag2, lag3, lag4 and lag5) and moving averages of 2-day, 3-day, 4-day, 5-day and 6-day (lag01, lag02, lag03, lag04 and lag05). The lagged effects and cumulative effects of each pollutant on RDs outpatient visits were calculated. In addition, we developed two-pollutant models [17] and conducted multicollinearity diagnosis. For two pollutants without obvious collinearity, two-pollutant models were constructed on the lag day with the maximum effect estimates adding the other air pollutant to check whether the associations were still significant. Subgroup analyses were conducted according to gender (male and female), age group ( $<18$ years, $18-44$ years, $45-64$ years and $>64$ years), and the type of RDs (acute RDs and chronic RDs). Pneumonia and acute bronchitis were defined as acute RDs. Asthma and chronic bronchitis 
were defined as chronic RDs. All results were expressed as the percentage changes in daily outpatient visits and its $95 \%$ CIs associated with a $10 \mu \mathrm{g} / \mathrm{m}^{3}$ increase in air pollutants [18]. All statistical analyses were conducted using $\mathrm{R}$ software version 3.4.4 (https://www.r-project.org). The "mgcv" package was used to fit the GAM model. In all analyses, $P$ values $<0.05$ were considered statistically significant.

\section{Results}

Table 1 summarizes the basic descriptive information of the daily air pollutants, meteorological parameters and outpatient visits. During the study period, the mean pollutant concentrations were $93.5 \mu \mathrm{g} / \mathrm{m}^{3}$ for $\mathrm{PM}_{2.5}$, $166.1 \mu \mathrm{g} / \mathrm{m}^{3}$ for $\mathrm{PM}_{10}, 68.8 \mu \mathrm{g} / \mathrm{m}^{3}$ for $\mathrm{SO}_{2}, 52.9 \mu \mathrm{g} / \mathrm{m}^{3}$ for $\mathrm{NO}_{2}, 1384 \mu \mathrm{g} / \mathrm{m}^{3}$ for $\mathrm{CO}$, and $101.3 \mu \mathrm{g} / \mathrm{m}^{3}$ for $\mathrm{O}_{3}$. The mean temperature, humidity, pressure and wind speed were $15^{\circ} \mathrm{C}, 56.3 \%, 996.5 \mathrm{kPa}$ and $2.5 \mathrm{~m} / \mathrm{s}$, respectively. A total of $1,373,658$ outpatient visits for RDs were identified, with an average of 752 outpatients per day.
The majority of the outpatients were male, less than 45 years old and diagnosed with acute bronchitis.

The spearman correlation coefficients between air pollutants and meteorological parameters are shown in Table 2. Each of the meteorological parameter significantly correlated with air pollutants. Temperature negatively and pressure positively correlated with the concentrations of $\mathrm{PM}_{2.5}, \mathrm{PM}_{10}, \mathrm{SO}_{2}, \mathrm{NO}_{2}$, and CO. Besides, the air pollutants were significantly correlated with each other. These results indicated that the confounding effects of the meteorological parameters and the effects of other air pollutants should be controlled in models.

Figure 1 (with detailed data in Additional file 1: Table S1) shows the percentage changes in outpatient visits for RDs associated with a $10 \mu \mathrm{g} / \mathrm{m}^{3}$ increase in concentration of each pollutant for different lag structures. In single-day lags models, an increase of $10 \mu \mathrm{g} / \mathrm{m}^{3}$ of $\mathrm{PM}_{2.5}$ and $\mathrm{PM}_{10}$ was associated with an increase of $0.159 \%$ (95\% CI, 0.035 $0.284 \%$ ) and $0.122 \%$ (95\% CI, $0.042-0.202 \%)$ in outpatient visits in the concurrent day, respectively. $\mathrm{PM}_{2.5}$ and $\mathrm{PM}_{10}$

Table 1 Descriptive statistics on daily air pollutants, meteorological parameters and outpatient visits in Jinan, China, 2012-2016

\begin{tabular}{|c|c|c|c|c|c|c|}
\hline Variable & Mean \pm SD & Min & $P_{25}$ & $P_{50}$ & $P_{75}$ & Max \\
\hline \multicolumn{7}{|l|}{ Pollutants $\left(\mu \mathrm{g} / \mathrm{m}^{3}\right)$} \\
\hline $\mathrm{PM}_{2.5}$ & $93.47 \pm 56.37$ & 14.90 & 56.00 & 80.00 & 113.00 & 443.00 \\
\hline $\mathrm{PM}_{10}$ & $166.05 \pm 79.85$ & 29.10 & 113.00 & 150.00 & 202.50 & 693.00 \\
\hline $\mathrm{SO}_{2}$ & $68.75 \pm 50.30$ & 12.00 & 36.00 & 52.00 & 86.00 & 429.00 \\
\hline $\mathrm{NO}_{2}$ & $52.94 \pm 21.12$ & 13.00 & 38.00 & 49.00 & 64.00 & 165.00 \\
\hline $\mathrm{CO}$ & $138.40 \pm 640.23$ & 445.00 & 975.50 & 1221.00 & 1590.00 & 6555.00 \\
\hline $\mathrm{O}_{3}$ & $101.32 \pm 59.03$ & 9.90 & 53.00 & 89.00 & 143.00 & 285.00 \\
\hline \multicolumn{7}{|c|}{ Meteorological parameters } \\
\hline Temperature $\left({ }^{\circ} \mathrm{C}\right)$ & $15.04 \pm 10.50$ & -12.40 & 5.50 & 17.10 & 24.10 & 34.00 \\
\hline Humidity (\%) & $56.26 \pm 19.43$ & 13.00 & 41.00 & 55.00 & 70.00 & 100.00 \\
\hline Pressure (kPa) & $996.52 \pm 9.11$ & 975.70 & 988.70 & 996.60 & 1003.70 & 1021.80 \\
\hline Wind speed (m/s) & $2.47 \pm 1.07$ & 0.20 & 1.70 & 2.20 & 3.00 & 8.40 \\
\hline \multicolumn{7}{|c|}{ Outpatient visits (cases/per day) } \\
\hline Total & $752.00 \pm 250.00$ & 349.00 & 580.00 & 680.00 & 828.00 & 1631.00 \\
\hline Male & $457.00 \pm 153.00$ & 210.00 & 353.00 & 413.00 & 503.00 & 1021.00 \\
\hline Female & $294.00 \pm 100.00$ & 120.00 & 225.00 & 267.00 & 327.00 & 643.00 \\
\hline \multicolumn{7}{|l|}{ Age } \\
\hline$<18 y$ & $281.90 \pm 116.25$ & 128.00 & 204.00 & 240.00 & 321.50 & 780.00 \\
\hline $18-44 y$ & $260.80 \pm 96.26$ & 88.00 & 191.00 & 235.00 & 311.00 & 593.00 \\
\hline $45-64 y$ & $120.50 \pm 39.30$ & 38.00 & 93.00 & 116.00 & 141.00 & 282.00 \\
\hline$>64 y$ & $88.62 \pm 38.32$ & 18.00 & 59.00 & 83.00 & 111.00 & 276.00 \\
\hline \multicolumn{7}{|l|}{ Diagnosis } \\
\hline Acute bronchitis & $506.00 \pm 179.83$ & 211.00 & 380.00 & 458.00 & 568.50 & 1152.00 \\
\hline Pneumonia & $195.87 \pm 80.36$ & 65.00 & 140.00 & 169.00 & 232.00 & 482.00 \\
\hline Asthma & $27.45 \pm 15.57$ & 2.00 & 17.00 & 24.00 & 35.00 & 113.00 \\
\hline Chronic bronchitis & $22.20 \pm 15.10$ & 0.00 & 11.00 & 20.00 & 30.00 & 97.00 \\
\hline
\end{tabular}

SD Standard deviation, Min minimum, Max Maximum, $P_{25}$ 25th percentile, $P_{50} 50$ th percentile, $P_{75} 75$ th percentile; 
Table 2 Spearman correlation coefficients between air pollutants and meteorological parameters in Jinan, China, 2012-2016

\begin{tabular}{|c|c|c|c|c|c|c|c|c|c|c|}
\hline & $\mathrm{PM}_{2.5}$ & $\mathrm{PM}_{10}$ & $\mathrm{SO}_{2}$ & $\mathrm{NO}_{2}$ & $\mathrm{CO}$ & $\mathrm{O}_{3}$ & Temperature & Humidity & Pressure & Wind speed \\
\hline$\overline{\mathrm{PM}_{2.5}}$ & 1 & $0.863^{* *}$ & $0.606^{* *}$ & $0.642^{* *}$ & $0.781^{* *}$ & $-0.182^{* *}$ & $-0.269^{* *}$ & $0.131^{* *}$ & $0.238^{* *}$ & $-0.236^{* *}$ \\
\hline $\mathrm{PM}_{10}$ & & 1 & $0.613^{* *}$ & $0.683^{* *}$ & $0.670^{* *}$ & $-0.125^{* *}$ & $-0.235^{* *}$ & $-0.116^{* *}$ & $0.223^{* *}$ & $-0.127^{* *}$ \\
\hline $\mathrm{SO}_{2}$ & & & 1 & $0.702^{* *}$ & $0.674^{* *}$ & $-0.344^{* *}$ & $-0.588^{* *}$ & $-0.293^{* *}$ & $0.532^{* *}$ & -0.036 \\
\hline $\mathrm{NO}_{2}$ & & & & 1 & $0.782^{* *}$ & $-0.459^{* *}$ & $-0.524^{* *}$ & $-0.069^{* *}$ & $0.557^{* *}$ & $-0.391^{* *}$ \\
\hline $\mathrm{CO}$ & & & & & 1 & $-0.435^{* *}$ & $-0.455^{* *}$ & $0.172^{* *}$ & $0.414^{* *}$ & $-0.385^{* *}$ \\
\hline $\mathrm{O}_{3}$ & & & & & & 1 & $0.794^{* *}$ & $-0.099^{* *}$ & $-0.679^{* *}$ & $0.199^{* *}$ \\
\hline Temperature & & & & & & & 1 & $0.179^{* *}$ & $-0.885^{* *}$ & $0.067^{* *}$ \\
\hline Humidity & & & & & & & & 1 & $-0.239^{* *}$ & $-0.354^{* *}$ \\
\hline Pressure & & & & & & & & & 1 & $-0.119^{* *}$ \\
\hline Wind speed & & & & & & & & & & 1 \\
\hline
\end{tabular}
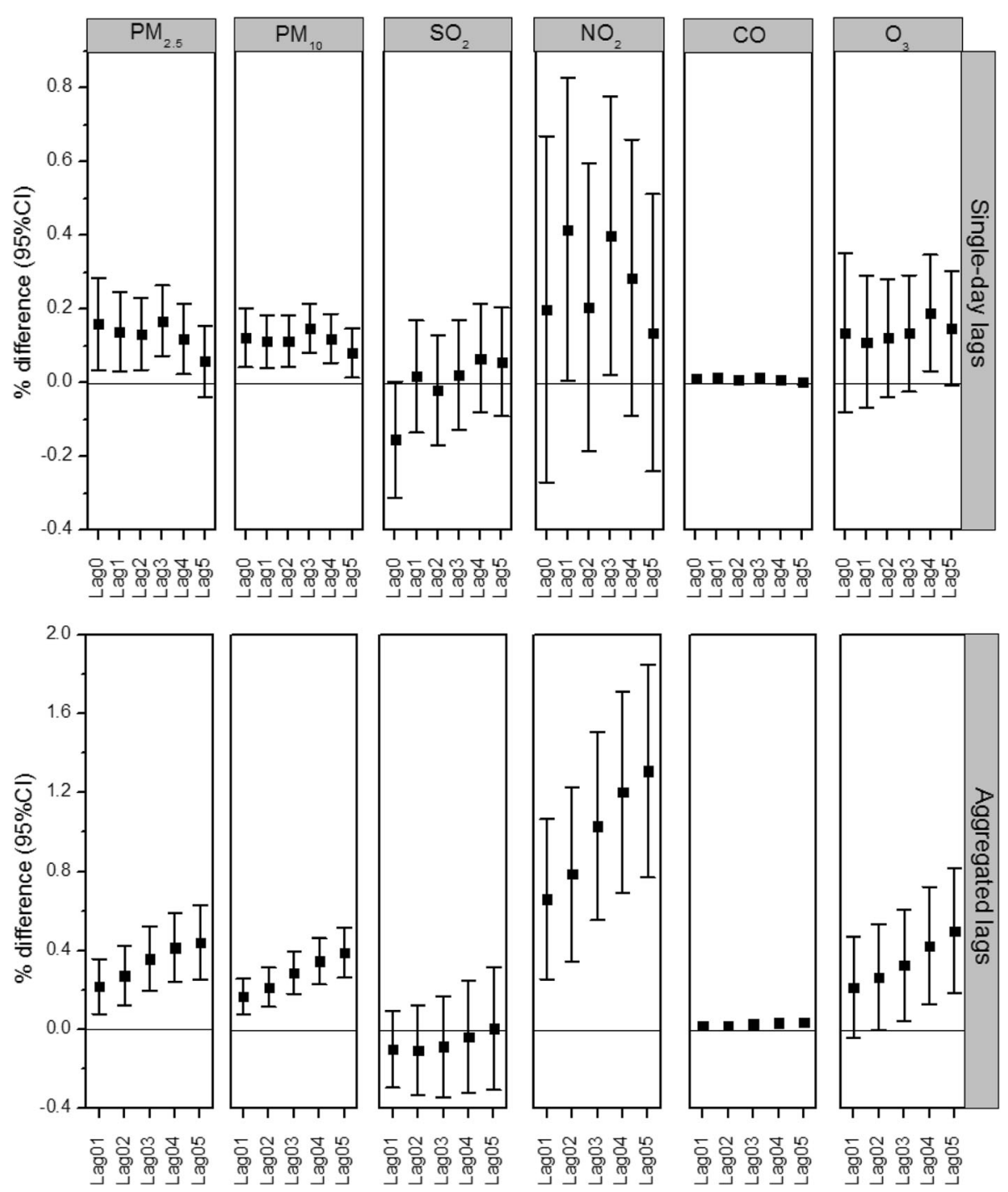

Fig. 1 Percentage changes in outpatient visits for RDs associated with a $10 \mu \mathrm{g} / \mathrm{m}^{3}$ increase in concentration of each pollutant 
showed similar lag patterns in association with outpatient visits for RDs. The effect estimates of $\mathrm{PM}_{2.5}$ and $\mathrm{PM}_{10}$ concentrations increased from lag day 0 to 3 , and peaked at lag day 3 , then decreased to lag day 5 . The maximum estimates for the effects of $\mathrm{PM}_{2.5}$ and $\mathrm{PM}_{10}$ were $0.168 \%$ (95\% CI, $0.072-0.265 \%$ ) and $0.149 \%$ (95\% CI, 0.082-0.215\%), respectively. Additionally, $\mathrm{NO}_{2}, \mathrm{CO}$ and $\mathrm{O}_{3}$ were also associated with outpatient visits, the maximum estimates for the effects of were $0.527 \%$ (95\% CI, $0.211-0.843 \%$ ), $0.013 \%$ (95\% CI, $0.003-0.023 \%$ ), and $0.189 \%$ (95\% CI, $0.032-$ $0.347 \%$ ), respectively. $\mathrm{SO}_{2}$ was not associated with outpatient visits. In aggregated lags models, the pooled effect estimates from lag day 0 to 5 for $\mathrm{PM}_{2.5}$ and $\mathrm{PM}_{10}$ were $0.441 \%$ (95\% CI, $0.251-0.632 \%$ ) and $0.388 \%$ (95\% CI, $0.261-0.514 \%)$, respectively.

Table 3 compares the maximum effect estimates of air pollutants using single-pollutant models and two-pollutant models. The effect estimates of $\mathrm{PM}_{2.5}$ were still significant after adding $\mathrm{SO}_{2}, \mathrm{CO}$ and $\mathrm{O}_{3}$ in two-pollutant models. However, the effect of $\mathrm{PM}_{2.5}$ lose its statistical significance after adjusting for $\mathrm{NO}_{2}$. After adding other air pollutants, the effects for $\mathrm{PM}_{10}$ remained significant, indicating that the association between $\mathrm{PM}_{10}$ and outpatient visits for RDs was robust. For $\mathrm{SO}_{2}$, when $\mathrm{PM}_{2.5}, \mathrm{NO}_{2}$ and $\mathrm{CO}$ were introduced separately, a negative association with outpatient visits was observed.

Additional file 1: Table S2 and Table S3 presents the effect estimates of $\mathrm{PM}_{2.5}$ and $\mathrm{PM}_{10}$ across different gender and age groups. The maximum effect estimates of $\mathrm{PM}_{2.5}$ and $\mathrm{PM}_{10}$ appeared at lay day 3 in both males and females. Among 4 age groups, the maximum effect estimate of $\mathrm{PM}_{2.5}$ and $\mathrm{PM}_{10}$ was observed for outpatients older than 64 years (at lay day 3 ) and for outpatients aged between 45 and 64 years (at lay day 4), respectively.

Additional file 1: Table S4 compares the associations of PM with two types of RDs. $\mathrm{PM}_{2.5}$ and $\mathrm{PM}_{10}$ were associated with acute RDs only. The maximum effect estimates were observed at lay day 3. No significant association of $\mathrm{PM}_{2.5}$ or $\mathrm{PM}_{10}$ was observed for chronic RDs.

\section{Discussion}

In the present study, we found that outdoor air pollutants $\left(\mathrm{PM}_{2.5}, \mathrm{PM}_{10}, \mathrm{NO}_{2}, \mathrm{CO}\right.$ and $\left.\mathrm{O}_{3}\right)$ were associated with increases in daily outpatient visits for RDs. Most of the associations remained significant after using different lag structure or adjusting for other pollutants. In single-day lag model, the effect estimates of $\mathrm{PM}_{2.5}$ and $\mathrm{PM}_{10}$ peaked at lay day 3. Significant effect modification by the type of RDs were observed. $\mathrm{PM}_{2.5}$ and $\mathrm{PM}_{10}$ were significantly associated with acute RDs including pneumonia and acute bronchitis. No significant associations were observed for chronic RDs.

The studies on air pollution and outpatient visits mainly conducted in China, because hospital health service is accessible to all patients and usually first-come first-served [21]. Previous studies focused on different air pollutants

Table 3 The maximum effect estimates of air pollutants using single-pollutant models and two-pollutant models

\begin{tabular}{|c|c|c|c|c|c|c|}
\hline Lag day & Single-pollutant model & Two-pollutant model & Two-pollutant model & Two-pollutant model & Two-pollutant model & Two-pollutant model \\
\hline $\mathrm{PM}_{2.5}$ & $\mathrm{PM}_{2.5}$ & $\mathrm{PM}_{2.5}+\mathrm{SO}_{2}$ & $\mathrm{PM}_{2.5}+\mathrm{NO}_{2}$ & $\mathrm{PM}_{2.5}+\mathrm{CO}$ & $\mathrm{PM}_{2.5}+\mathrm{O}_{3}$ & \\
\hline $\operatorname{Lag} 3$ & $0.168(0.072,0.265)^{*}$ & $0.217(0.105,0.328)^{*}$ & $0.094(-0.042,0.231)$ & $0.183(0.001,0.366)^{*}$ & $0.168(0.072,0.265)^{*}$ & \\
\hline Lag05 & $0.441(0.251,0.632) *$ & $0.566(0.343,0.770)^{*}$ & $0.235(-0.024,0.495)$ & $0.481(0.127,0.836)^{*}$ & $0.423(0.233,0.613)^{*}$ & \\
\hline $\mathrm{PM}_{10}$ & $\mathrm{PM}_{10}$ & $\mathrm{PM}_{10}+\mathrm{SO}_{2}$ & $\mathrm{PM}_{10}+\mathrm{NO}_{2}$ & $\mathrm{PM}_{10}+\mathrm{CO}$ & $\mathrm{PM}_{10}+\mathrm{O}_{3}$ & \\
\hline Lag 3 & $0.149(0.082,0.215)^{*}$ & $0.199(0.121,0.277)^{*}$ & $0.133(0.037,0.230)^{*}$ & $0.197(0.088,0.307)^{*}$ & $0.146(0.079,0.212)^{*}$ & \\
\hline Lag05 & $0.388(0.261,0.514)^{*}$ & $0.501(0.357,0.645)^{*}$ & $0.339(0.159,0.520)^{*}$ & $0.477(0.284,0.669)^{*}$ & $0.368(0.240,0.496)^{*}$ & \\
\hline $\mathrm{SO}_{2}$ & $\mathrm{SO}_{2}$ & $\mathrm{SO}_{2}+\mathrm{PM}_{2.5}$ & $\mathrm{SO}_{2}+\mathrm{NO}_{2}$ & $\mathrm{SO}_{2}+\mathrm{CO}$ & $\mathrm{SO}_{2}+\mathrm{O}_{3}$ & $\mathrm{SO}_{2}+\mathrm{PM}_{10}$ \\
\hline $\operatorname{Lag} 4$ & $0.066(-0.082,0.214)$ & $-0.038(-0.210,0.134)$ & $-0.198(-0.412,0.017)$ & $-0.041(-0.226,0.144)$ & $0.080(-0.068,0.229)$ & $-0.106(-0.280,0.068)$ \\
\hline Lag05 & $0.004(-0.308,0.316)$ & $\begin{array}{l}-0.410(-0.756 \\
-0.063)^{*}\end{array}$ & $\begin{array}{l}-1.091(-1.527 \\
-0.653)^{*}\end{array}$ & $\begin{array}{l}-0.420(-0.783 \\
-0.056)^{*}\end{array}$ & $0.014(-0.297,0.325)$ & $\begin{array}{l}-0.578(-0.926 \\
-0.229)\end{array}$ \\
\hline $\mathrm{NO}_{2}$ & $\mathrm{NO}_{2}$ & $\mathrm{NO}_{2}+\mathrm{PM}_{2.5}$ & $\mathrm{NO}_{2}+\mathrm{SO}_{2}$ & $\mathrm{NO}_{2}+\mathrm{CO}$ & $\mathrm{NO}_{2}+\mathrm{O}_{3}$ & $\mathrm{NO}_{2}+\mathrm{PM}_{10}$ \\
\hline Lag 1 & $0.527(0.211,0.843)^{*}$ & $0.459(0.034,0.885)^{*}$ & $0.995(0.550,1.442)^{*}$ & $0.516(0.005,1.030)^{*}$ & $0.563(0.245,0.882)^{*}$ & $0.361(-0.080,0.805)$ \\
\hline Lag05 & $1.310(0.770,1.852)^{*}$ & $0.853(0.119,1.592)^{*}$ & $2.689(1.911,3.473)^{*}$ & $1.225(0.429,2.027)^{*}$ & $1.336(0.798,1.877)^{*}$ & $0.286(-0.471,1.049)$ \\
\hline $\mathrm{CO}$ & $\mathrm{CO}$ & $\mathrm{CO}+\mathrm{PM}_{2.5}$ & $\mathrm{CO}+\mathrm{SO}_{2}$ & $\mathrm{CO}+\mathrm{NO}_{2}$ & $\mathrm{CO}+\mathrm{O}_{3}$ & $\mathrm{CO}+\mathrm{PM}_{10}$ \\
\hline Lag 1 & $0.013(0.003,0.023)^{*}$ & $0.0008(-0.009,0.025)$ & $0.019(0.007,0.031)^{*}$ & $0.000(-0.016,0.016)$ & $0.014(0.004,0.024)^{*}$ & $0.003(-0.013,0.019)$ \\
\hline Lag05 & $0.034(0.016,0.051)^{*}$ & $-0.004(-0.038,0.029)$ & $0.046(0.025,0.067)^{*}$ & $0.004(-0.023,0.030)$ & $0.038(0.020,0.056)^{*}$ & $-0.016(-0.043,0.010)$ \\
\hline $\mathrm{O}_{3}$ & $\mathrm{O}_{3}$ & $\mathrm{O}_{3}+\mathrm{PM}_{2.5}$ & $\mathrm{O}_{3}+\mathrm{SO}_{2}$ & $\mathrm{O}_{3}+\mathrm{CO}$ & $\mathrm{O}_{3}+\mathrm{NO}_{2}$ & $\mathrm{O}_{3}+\mathrm{PM}_{10}$ \\
\hline Lag4 & $0.189(0.031,0.347)^{*}$ & $0.188(0.031,0.346)^{*}$ & $0.196(0.038,0.354)^{*}$ & $0.226(0.066,0.387)^{*}$ & $0.221(0.063,0.380)^{*}$ & $0.171(0.014,0.329)^{*}$ \\
\hline Lag05 & $0.499(0.183,0.815)^{*}$ & $0.452(0.138,0.767)^{*}$ & $0.499(0.183,0.816)^{*}$ & $0.593(0.276,0.911)^{*}$ & $0.522(0.208,0.837)^{*}$ & $0.383(0.068,0.699)^{*}$ \\
\hline
\end{tabular}


and different RDs. To a large extent, our results were consistent with previous studies [18, 22-24]. For example, a recent case-crossover study in Beijing, found that $\mathrm{PM}_{2.5}$, $\mathrm{PM}_{10}, \mathrm{NO}_{2}$ and $\mathrm{CO}$ were positively associated with outpatient visits for four kinds of acute respiratory outcomes [24]. A time-series analysis in Shanghai showed that the effect estimates for $\mathrm{NO}_{2}$ were the greatest in magnitude in association with various RDs; additionally, air pollutants were not associated with chronic RDs such as asthma and chronic obstructive pulmonary disease [18]. In this study, we found that exposure to $\mathrm{PM}_{2.5}$ and $\mathrm{PM}_{10}$ had significantly instant effects on outpatient visits, and the effects lasted for 5-6 days and peaked at 3 days later. Previous studies have been found that PM had instant effect [25], lag effect $[26,27]$ or both effects [28] on outpatient visits for RDs. The difference of these conclusions might due to study population, sample size, or statistical methods.

The mechanisms linking exposure to PM and potential health consequences have been widely studied. $\mathrm{PM}_{10}$, especially $\mathrm{PM}_{2.5}$, can be inhaled deeply into the human lung, which attribute to PM a high toxicity. The inflammatory response is considered to be a key point to understand the pathogenesis of diseases [29]. $\mathrm{PM}_{2.5}$ exposure has been associated with various inflammatory biomarkers, including exhaled nitric oxide level [30, 31], neutrophils and IL-8 levels in nasal lavage fluid [32] and the levels of inflammatory cytokines produced by human airway epithelial cells [33]. The local inflammation caused by PM in the alveoli could further develop into a systemic inflammatory state [34], which is an essential event for many diseases.

In this study, $\mathrm{SO}_{2}$ was not associated with $\mathrm{RDs}$ in single-pollutant models. After adjusting for $\mathrm{PM}_{2.5}, \mathrm{NO}_{2}$ and $\mathrm{CO}$ in two-pollutant model, negative associations between $\mathrm{SO}_{2}$ and $\mathrm{RDs}$ were observed. Previous studies on exposure to $\mathrm{SO}_{2}$ and RDs have yielded mixed results. A time-series analysis in Jinan showed that an increase of $10 \mu \mathrm{g} / \mathrm{m}^{3}$ in $\mathrm{SO}_{2}$ was associated with $1.69 \%(95 \% \mathrm{CI}$, $1.56-1.83 \%)$ increase in daily non-accidental mortality rate [12]. Another recent study showed strong association between $\mathrm{SO}_{2}$ and outpatient visits for RDs in southeastern China [35]. In addition, several studies reported a null association [22, 36]. However, in line with the present study, another study found that outdoor $\mathrm{SO}_{2}$ significantly associated with the reduced risk of initial outpatient visits for tuberculosis, suggesting short-term protective effects of $\mathrm{SO}_{2}$ exposure on bacteria-induced pulmonary infections [37]. The inconsistency of conclusions may be explained by differences in compositions of air pollutants or individual sensitivity [35]. The effects of $\mathrm{SO}_{2}$ need to be confirmed in future large-scale population based studies.

In the present study, the majority of the outpatients were males and less than 45 years old. Literatures have shown that males have less mature lungs and relatively narrower airways compared with females $[38,39]$. Besides, children have insufficient antioxidant defenses and weakened ability of scavenging exogenous toxicants [40]. Therefore, males and younger people may have a higher susceptibility for damage by exposure to air pollutants even when outdoor air pollutants concentrations are not high. These factors could possibly contribute to the large number of daily outpatients among males and younger people. However, in gender-specific analysis, the associations of $\mathrm{PM}_{2.5}$ and $\mathrm{PM}_{10}$ were significant both in males and females. In age-specific analysis, the magnitudes of the effect estimates of PMs were greater in older people, which indicated that with the concentrations of PMs increased, the number of older outpatients saw larger growth. This evidence suggested that older people should minimize their outdoor activities and pay more attention on personal protection when outdoor PMs concentrations are high. We found $\mathrm{PM}_{2.5}$ and $\mathrm{PM}_{10}$ were significantly associated with acute RDs only. One of the explanations might be that the daily count of outpatient visits for acute RDs was much larger than that for chronic RDs (702 for acute RDs vs. 50 for chronic RDs per day). Other unknown mechanisms underlying the associations of PM with acute and chronic RDs might exist and need to be further investigated.

The strengths of our study are noteworthy. First, compared to the majority of previous studies that focused on a selected population (such as children) or a specific diagnosis, our study was characterized by the diversity of RDs diagnoses, the representation of the general population, and long time span. Second, to reduce the selection bias as much as possible, we collected data from five hospitals in Jinan city. Third, the large sample size enabled us to examine the nonlinear association between air pollutant exposures and outpatient visits for RDs and to further investigate the effect modification by gender, age group and the type of RDs. Nevertheless, our study has some limitations. Our study focused on one city in China, so the results should be interpreted with caution for other city or population. Another limitation is that unknown or unmeasured confounders such as smoking status, vaccinations and so on may exist and contributed to the associations.

\section{Conclusions}

In conclusion, the present study suggested that outdoor air pollution associated with increased risk of outpatient visits for RDs in China. $\mathrm{PM}_{2.5}$ and $\mathrm{PM}_{10}$ showed instant and continuous effects, while $\mathrm{NO}_{2}, \mathrm{CO}$ and $\mathrm{O}_{3}$ showed delayed effects on outpatient visits for RDs. Besides, PMs showed significant associations with acute RDs 
only. Ongoing efforts are required to better understand the adverse effects of outdoor air pollution on public health and to develop feasible preventive approaches.

\section{Additional file}

Additional file 1: Table S1 Percentage changes in outpatient visits for RDs associated with a $10 \mu \mathrm{g} / \mathrm{m}^{3}$ increase in concentration of each pollutant in using different lag structures in single-pollutant models. Table S2 Percentage changes in outpatient visits for RDs associated with a $10 \mu \mathrm{g} / \mathrm{m}^{3}$ increase in concentration of $\mathrm{PM}_{2.5}$ across different gender and age groups. Table S3 Percentage changes in outpatient visits for RDs associated with a $10 \mu \mathrm{g} / \mathrm{m}^{3}$ increase in concentration of $\mathrm{PM}_{10}$ across different gender and age groups. Table S4 Percentage changes in outpatient visits for different type of RDs associated with a $10 \mu \mathrm{g} / \mathrm{m}^{3}$ increase in concentration of $\mathrm{PM}_{2.5}$ and $\mathrm{PM}_{10}$. (DOC $108 \mathrm{~kb}$ )

\section{Abbreviations}

AIC: Akaike's information criterion; Cl: Confidence interval; CO: Carbon monoxide; DOW: Day of the week; GAM: Generalized additive model; Max: Maximum; Min: minimum; $\mathrm{NO}_{2}$ : Nitrogen dioxides; $\mathrm{O}_{3}$ : Ozone; $\mathrm{P}_{25}$ : 25th percentile; $P_{50}$ : 50th percentile; $P_{75}$ : 75 th percentile; $P M$ : Particle matter; $\mathrm{PM}_{10}$ : Particle matter $\leq 10-\mu \mathrm{m}$ in diameter; $\mathrm{PM}_{2.5}$ : Particle matter $\leq 2.5-\mu \mathrm{m}$ in diameter; RDs: Respiratory diseases; SD: Standard deviation; $\mathrm{SO}_{2}$ : Sulfur dioxide

\section{Acknowledgements}

Not applicable.

\section{Funding}

This work was supported by the Key Research \& Development Program of Shandong Province (2017GSF218052) and Technology Development Plan Project of Jinan City (201704100)

\section{Availability of data and materials}

Data can be available through contact with the corresponding author.

\section{Authors' contributions}

$Y L$ and $H L$ designed the research and had primary responsibility for the final content of the manuscript; SW, YL, AN, WS and JL conducted the research; $\mathrm{YL}$ analyzed the data; and SW interpreted the results and wrote the manuscript. All authors read and approved the final manuscript.

\section{Ethics approval and consent to participate}

Data were collected from administrative departments rather than human subjects. No personal private information was involved.

\section{Consent for publication}

Not applicable.

\section{Competing interests}

The authors declare that they have no competing interests.

\section{Publisher's Note}

Springer Nature remains neutral with regard to jurisdictional claims in published maps and institutional affiliations.

\section{Author details}

${ }^{1}$ Department of Public Health, Shandong Provincial Hospital affiliated to Shandong University, Jinan 250021, Shandong, China. ${ }^{2}$ Department of Respiratory Medicine, Shandong Provincial Hospital affiliated to Shandong University, Jinan 250021, Shandong, China. ${ }^{3}$ Department of Respiratory Medicine, School of Clinical Medicine, Shandong University, Jinan 250012, Shandong, China. ${ }^{4}$ Department of Respiratory Medicine, University of Jinan, Jinan 250022, Shandong, China. ${ }^{5}$ Department of Biostatistics, School of Public Health, Shandong University, Jinan 250012, Shandong, China.
Received: 10 August 2018 Accepted: 30 November 2018

Published online: 12 December 2018

\section{References}

1. Yang BY, Qian ZM, Li S, Chen G, Bloom MS, Elliott M, et al. Ambient air pollution in relation to diabetes and glucose-homoeostasis markers in China: a cross-sectional study with findings from the 33 communities Chinese health study. Lancet Planet Health. 2018;2(2):e64-73.

2. Chen G, Li S, Zhang Y, Zhang W, Li D, Wei X, et al. Effects of ambient PM1 air pollution on daily emergency hospital visits in China: an epidemiological study. Lancet Planet Health. 2017;1(6):e221-9.

3. Qiu H, Pun VC, Tian L. Short-term effects of fine and coarse particles on deaths in Hong Kong elderly population: An analysis of mortality displacement. Environ Pollut. 2018;241:148-54.

4. He Y, Gao Z, Guo T, Qu F, Liang D, Li D, et al. Fine particulate matter associated mortality burden of lung cancer in Hebei Province, China. Thorac Cancer. 2018;9(7):820-6.

5. Wang $Y, Z u Y$, Huang L, Zhang H, Wang C, Hu J. Associations between daily outpatient visits for respiratory diseases and ambient fine particulate matter and ozone levels in Shanghai, China. Environ Pollut. 2018:240:754-63.

6. Guo H, Chen M. Short-term effect of air pollution on asthma patient visits in Shanghai area and assessment of economic costs. Ecotoxicol Environ Saf. 2018;161:184-9.

7. An Z, Jin Y, Li J, Li W, Wu W. Impact of particulate air pollution on cardiovascular health. Curr Allergy Asthma Rep. 2018;18(3):15.

8. Guo $P$, Wang $Y$, Feng W, Wu J, Fu C, Deng $H$, et al. Ambient air pollution and risk for ischemic stroke: a short-term exposure assessment in South China. Int J Environ Res Public Health. 2017;14(9):E1091.

9. He J, Gong S, Yu Y, Yu L, Wu L, Mao H, et al. Air pollution characteristics and their relation to meteorological conditions during 2014-2015 in major Chinese cities. Environ Pollut. 2017;223:484-96.

10. Liu Y, He K, Li S, Wang Z, Christiani DC, Koutrakis P. A statistical model to evaluate the effectiveness of PM2.5 emissions control during the Beijing 2008 Olympic games. Environ Int. 2012;44:100-5.

11. Schwartz J, Bellinger D, Glass T. Exploring potential sources of differential vulnerability and susceptibility in risk from environmental hazards to expand the scope of risk assessment. Am J Public Health. 2011;101 Suppl:S94-101.

12. Zhang J, Liu Y, Cui LL, Liu SQ, Yin XX, Li HC. Ambient air pollution, smog episodes and mortality in Jinan, China. Sci Rep. 2017;7(1):11209.

13. Liu P, Wang X, Fan J, Xiao W, Wang Y. Effects of air pollution on hospital emergency room visits for respiratory diseases: urban-suburban differences in eastern China. Int J Environ Res Public Health. 2016;13(3):341.

14. Wang W, Ying Y, Wu Q, Zhang H, Ma D, Xiao WA. GIS-based spatial correlation analysis for ambient air pollution and AECOPD hospitalizations in Jinan, China. Respir Med. 2015;109(3):372-8.

15. Hastie T, Tibshirani R. Generalized additive models for medical research. Stat Methods Med Res. 1995;4(3):187-96.

16. Dominici F, McDermott A, Zeger SL, Samet JM. On the use of generalized additive models in time-series studies of air pollution and health. Am J Epidemiol. 2002;156(3):193-203.

17. Xu Q, Wang S, Guo Y, Wang C, Huang F, Li X, et al. Acute exposure to fine particulate matter and cardiovascular hospital emergency room visits in Beijing, China. Environ Pollut. 2017;220:317-27.

18. Zhang $H$, Niu $Y$, Yao $Y$, Chen $R$, Zhou $X$, Kan $H$. The impact of ambient air pollution on daily hospital visits for various respiratory diseases and the relevant medical expenditures in Shanghai, China. Int J Environ Res Public Health. 2018;15(3):E425.

19. Wood S. Generalized Additive Models: An introduction with R. Boca Raton: CRC Press: 2006

20. Li Q, Wang HJ, Song Y, Ma J, Song JY, Guo Y. Association between children's forced vital capacity and long-term exposure to local ambient temperature in China: a national cross-sectional survey. Sci Total Environ. 2016;557-558:880-7.

21. Chen R, Chu C, Tan J, Cao J, Song W, Xu X, et al. Ambient air pollution and hospital admission in Shanghai, China. J Hazard Mater. 2010;181(1-3):234-40.

22. Lin M, Stieb DM, Chen Y. Coarse particulate matter and hospitalization for respiratory infections in children younger than 15 years in Toronto: a casecrossover analysis. Pediatrics. 2005:116(2):e235-40.

23. Wong TW, Tam W, Tak Sun YI, Wun YT, Wong AH, Wong CM. Association between air pollution and general practitioner visits for respiratory diseases in Hong Kong. Thorax. 2006;61(7):585-91. 
24. Li R, Jiang N, Liu Q, Huang J, Guo X, Liu F, et al. Impact of air pollutants on outpatient visits for acute respiratory outcomes. Int J Environ Res Public Health. 2017;14(1):47.

25. Liu Y, Xie S, Yu Q, Huo X, Ming X, Wang J, et al. Short-term effects of ambient air pollution on pediatric outpatient visits for respiratory diseases in Yichang city, China. Environ Pollut. 2017;227:116-24.

26. Li G, Lan H, Liu Z, Rui T, Lu J, Bian L, et al. The association between shortterm exposure to fine particulate matter and outpatient visit in Beijing, China. Iran J Public Health. 2017;46(11):1486-94.

27. Sinclair AH, Edgerton ES, Wyzga R, Tolsma DA. Two-time-period comparison of the effects of ambient air pollution on outpatient visits for acute respiratory illnesses. J Air Waste Manag Assoc. 2010;60(2):163-75.

28. Bai L, Su X, Zhao D, Zhang Y, Cheng Q, Zhang H, et al. Exposure to trafficrelated air pollution and acute bronchitis in children: season and age as modifiers. J Epidemiol Community Health. 2018:72(5):426-33.

29. Wu W, Jin Y, Carlsten C. Inflammatory health effects of indoor and outdoor particulate matter. J Allergy Clin Immunol. 2018;141(3):833-44.

30. Gong J, Zhu T, Kipen H, Wang G, Hu M, Guo Q, et al. Comparisons of ultrafine and fine particles in their associations with biomarkers reflecting physiological pathways. Environ Sci Technol. 2014;48(9):5264-73.

31. Han Y, Zhu T, Guan T, Zhu Y, Liu J, Ji Y, et al. Association between sizesegregated particles in ambient air and acute respiratory inflammation. Sc Total Environ. 2016;565:412-9.

32. Chen BY, Chan CC, Lee CT, Cheng TJ, Huang WC, Jhou JC, et al. The association of ambient air pollution with airway inflammation in school children. Am J Epidemiol. 2012;175(8):764-74.

33. Ohtoshi T, Takizawa H, Okazaki H, Kawasaki S, Takeuchi N, Ohta K, et al. Diesel exhaust particles stimulate human airway epithelial cells to produce cytokines relevant to airway inflammation in vitro. J Allergy Clin Immunol. 1998;101(6):778-85.

34. Li Y, Rittenhouse-Olson K, Scheider WL, Mu L. Effect of particulate matter air pollution on C-reactive protein: a review of epidemiologic studies. Rev Environ Health. 2012;27(2-3):133-49.

35. Mo Z, Fu Q, Zhang L, Lyu D, Mao G, Wu L, et al. Acute effects of air pollution on respiratory disease mortalities and outpatients in southeastern China. Sci Rep. 2018;8(1):3461

36. Lee SL, Wong WHS, Lau YL. Association between air pollution and asthma admission among children in Hong Kong. Clin Exp Allergy. 2006:36(9):1138-46.

37. Ge E, Fan M, Qiu H, Hu H, Tian L, Wang X, et al. Ambient sulfur dioxide levels associated with reduced risk of initial outpatient visits for tuberculosis: a population based time series analysis. Environ Pollut. 2017;228:408-15.

38. Becklake MR, Kauffmann F. Gender differences in airway behaviour over the human life span. Thorax. 1999:54(12):1119-38.

39. Dong GH, Chen T, Liu MM, Wang D, Ma YN, Ren WH, et al. Gender differences and effect of air pollution on asthma in children with and without allergic predisposition: northeast Chinese children health study. PLoS One. 2011;6(7):e22470.

40. DeVries R, Kriebel D, Sama S. Outdoor air pollution and COPD-related emergency department visits, hospital admissions, and mortality: a metaanalysis. COPD. 2017;14(1):113-21.

Ready to submit your research? Choose BMC and benefit from:

- fast, convenient online submission

- thorough peer review by experienced researchers in your field

- rapid publication on acceptance

- support for research data, including large and complex data types

- gold Open Access which fosters wider collaboration and increased citations

- maximum visibility for your research: over $100 \mathrm{M}$ website views per year

At $\mathrm{BMC}$, research is always in progress.

Learn more biomedcentral.com/submissions 